\title{
Política y MeRCado: LA CONVIVENCIA DEMOCRÁTICA EN ARGENTINA
}

\author{
Hugo Quiroga \\ Professor e investigador da Facultad de Ciencia Política \\ da Universidad Nacional de Rosario, Argentina.
}

E-mail: haquiroga@arnet.com.ar

\section{Resumen}

La ponencia procura examinar los dieciséis años de vida del régimen democrático argentino que debuta a fines de 1983.¿En qué punto se encuentra la democracia argentina?, ¿cuáles son los cambios más importantes que se han producido? Con este universo de referencia se tratará de problematizar el enlace entre entre Estado, mercado y sociedad civil. En el término de una década ha tenido lugar la transición del autoritarismo a la democracia y la transición de una economía dirigida a una economía de mercado. Al final del doble proceso de transición, la democracia y la economía de mercado, en una combinación inédita, deberán convivir buscando fórmulas de acción que favorezcan la continuidad de un poder legítimo, la igualdad social y un crecimiento sostenido. En este sentido, y aunque en el mundo se ha impuesto la economía de mercado, de lo que se trata es de discutir un reequilibrio entre Estado y mercado. Sin sospechar del Estado, nuestro lema será: más sociedad civil en lugar de más Estado o de más mercado. En estos reclamos se hallan los difíciles pero no imposibles avances de la democracia. El perfeccionamiento del sistema democrático dependerá en buena medida de su capacidad para aprender del pasado y de las decisiones orientadas al futuro.

Palabras clave: legitimidad; democracia; Argentina.

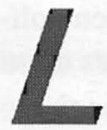

a democracia, como a veces sucede, decepciona. Se crean tan-

tas expectativas en torno a ella, que una vez instalada pareciera que son inevitables ciertos procesos de frustración. En este sentido, es muy reveladora la experiencia por la que pasaron los países del Este con posterioridad al colapso de 1989. Instauradas las instituciones democráticas no se resuelven automáticamente los problemas económicos y sociales. En América Latina la democracia se ha establecido con modalidades y procesos diferentes. Los pasos 
fundamentales hacia la democratización concluyeron en la década del 80 cuando la mayor parte de los países del Cono Sur adoptaron la democracia como régimen político. La tendencia imperante exigió a los gobiernos legitimidad democrática, dando lugar a un moderado optimismo sobre el futuro institucional del subcontinente. Aunque ese optimismo siga hoy en pie, no se puede desconocer que el principio de legitimidad democrática ha sido puesto a prueba en varios países sudamericanos por un cuadro de deterioro institucional que amenaza con la estabilidad democrática. La guerrilla y el narcotráfico (Colombia), el "cesarismo democrático" (Chávez, Fujimori, Banzer, Oviedo) y el golpismo (Perú, Ecuador, Paraguay) campean aún en nuestras naciones.

Detrás de situaciones todavía controlables, anidan las dificultades económicas de la región, el avance de una cultura política que descuida a las instituciones, la corrupción en la cumbre, las desigualdades vergonzantes y la desconfianza de los ciudadanos en su clase dirigente. Renace en el mundo de las ideas la vieja preocupación huntingtoniana por la estabilidad política. Son numerosos los líderes con pasado golpista que han llegado, quizá por la crisis de representación que aqueja a los partidos, a ocupar lugares prominentes en las estructuras ejecutivas y deliberativas de las nuevas democracias, legitimados por las bondades del sufragio universal. No hay que olvidar que América Latina cuenta con una historia repetida de fracasos. Por eso, en un contexto histórico que reconoce índices muy altos de desigualdad con insatisfacción institucional, nacen los temores de una erosión de la vida democrática.

En el caso argentino, la democracia que nace en 1983 no es ajena a las realidades y condiciones de su pasado: tanto el orden político restrictivo que la origina y condiciona como las vicisitudes de su historia mediata e inmediata. Pasado, presente y futuro de un mismo proceso histórico, abierto y en movimiento... Comprender las acciones contemporáneas es situarse en la perspectiva de un presente activo en su relación al pasado y con la mirada expectante hacia el futuro.

En las páginas que siguen me propongo examinar los dieciséis años de vida del régimen democrático que debuta a fines de 1983 , teniendo en cuenta los logros obtenidos, los problemas presentes y las 
tareas pendientes. Una mirada histórica de las principales cuestiones asociadas a la democratización de la sociedad resulta de gran ayuda para efectuar un balance político de este tramo que se recorta entre el autoritarismo militar y un futuro abierto, que señala las enormes tareas irresueltas. ¿En qué punto se encuentra la democracia argentina?, ¿cuáles son los cambios más importantes que se han producido? Con este universo de referencia se tratará de problematizar el enlace entre Estado, mercado y sociedad civil.

\section{Legitimidad democrática}

En la Argentina de fin de siglo se ha legitimado un poder democrático. Cuatro elecciones presidenciales consecutivas, desde el reestablecimiento de la democracia en 1983, avalan el crecimiento cívico de la sociedad. La experiencia del siglo XX nos ha enseñado, con nuestra historia repetida de fracasos (desobediencia de los militares al poder civil, proscripciones, fraude electoral y falta de alternancia) que la legitimación del poder político requiere tanto de instituciones estables como de la conformidad de la sociedad con las reglas de competencia pacífica, exigencias que otorgan validez a las actuaciones de ese poder.

Por eso, voy a caracterizar al período que se extiende entre 1930 y 1983 como de "prelegitimidad" (Ferrero, 1943, p.157-158) ${ }^{1}$ democrática, lapso en el cual ni los civiles ni los militares fueron totalmente respetuosos de las reglas de sucesión del poder establecidas en la Constitución Nacional. A partir del golpe de 1930 la legitimidad democrática se constituirá en el problema permanente de la Argentina contemporánea (Botana, 1998) ${ }^{2}$. Atrás ha quedado nuestra primera forma efectivamente democrática, una democracia de corta duración que se instaura entre 1916 y 1930.

\footnotetext{
' Aunque con modificaciones tomo la idea de prelegitimidad.

2 Mis ideas acerca de los problemas de la legitimidad democrática en la Argentina están inspiradas en el pensamiento de Natalio Botana. De manera particular, sus contínuas referencias a Guglielmo Ferrero me llevaron a la lectura del historiador italiano. Para el desarrollo del concepto de cuasi legitimidad en Ferrero, y algunas consideraciones sobre la realidad argentina.
} 
Según Guglielmo Ferrero (1943), la prelegitimidad es un estado preparatorio de la legitimidad, y para pasar de un estado a otro hace falta, antes que nada, tiempo. Pero el factor tiempo por si sólo no es suficiente. Es lo que advierte el propio Ferrero cuando señala que la legitimidad únicamente puede alcanzar plena madurez si existe una creencia activa en su principio. De esta manera, la legitimidad política entendida como el "derecho de gobernar" (Coicaud, 1997) engloba las nociones de tiempo y creencia. De un tiempo histórico, empírico, representado por la sucesión de meses y años y de un acuerdo de los ciudadanos a aceptar una autoridad política. Precisamente, lo que ha prevalecido entre los argentinos es una historia de sospechas y desencuentros de gobernantes y gobernados con sus instituciones democráticas.

La experiencia argentina posterior a los años treinta ha demostrado que la Ley Suprema, que establece las reglas de competencia pacífica por el poder, fue insuficiente para asegurar por sí misma gobiernos legítimos y durables. Los comportamientos pretorianos de la sociedad, las elecciones fraudulentas y las proscripciones políticas a lo largo del siglo XX revelan la poca convicción de ciudadanos y dirigentes sobre el derecho de gobernar de las instituciones democráticas. Es aquí donde se pone en evidencia que esas reglas formales no se legitiman "per se", automáticamente, sino sobre la base de un acuerdo que otorga validez a esos procedimientos e instituciones. A causa del débil reconocimiento a la ley y a sus instituciones, se conformó en el tiempo una cultura democrática inconsistente que, sin duda, se ha modificado a partir de 1983, como se verá más abajo.

¿Cuándo un gobierno es legítimo? Según Ferrero (1943), cuando el poder es conferido y ejercido de acuerdo con las reglas de sucesión aceptadas por todos sin discusión, tanto por el gobierno que las debe respetar como por aquellos que las deben obedecer. La idea que sostengo es que entre 1930 y 1983 no se pudo crear en nuestro país un sistema de legitimación del poder. En otras palabras, un poder regulado y encuadrado por un vínculo jurídico-institucional reconocido y aceptado por todos, que justifica el derecho legítimo y autoriza a tomar decisiones vinculantes para la sociedad.

A pesar de las marcas de nuestra historia, ¿se puede hablar hoy de un poder democrático legítimo? Pareciera que desde 1983 un poder 
con esas características se ha instalado entre nosotros. Este es el dato central, cuyo significado histórico explica la clausura del período de prelegitimidad que transcurre entre 1930 y 1983 y señala el nacimiento de una era en la cual la "legitimidad es el reconocimiento del derecho de gobernar"(Coicaud, 1997, p.13). ¿Cuáles son las razones del cambio? Aunque subsisten ciertos rasgos preocupantes, una transformación profunda se ha operado en nuestra cultura política a través del rechazo al autoritarismo militar y la inequívoca defensa de los gobernantes y gobernados al sistema democrático. La mejor prueba de esta afirmación se encuentra en el momento de la entrega anticipada del mando constitucional del presidente Alfonsín en 1989. Más allá de la crisis económica y del colapso hiperinflacionario, que genera el descontrol de la economía, los argentinos pudieron en ese trance distinguir entre la legitimidad del gobierno y la legitimidad del sistema. Ni los ciudadanos ni los dirigentes pensaron, como antaño, en los militares como alternativa de poder. En esto radica el éxito de la transición política.

Con toda razón escribe Gauchet que "la democracia es experiencia e historia", la democracia se desarrolla y transforma en el tiempo (Gauchet, 1995, p.22). Las sociedades aprenden de las experiencias concretas, y hay dos hechos trágicos de la historia de las últimas décadas que dejan sus enseñanzas en la vida política de los argentinos: la dictadura militar de 1976-1983 y la hiperinflación de 198990.La primera enseñó a valorar la permanencia de la democracia y la segunda a valorar la importancia de la estabilidad monetaria. La legitimidad de la democracia argentina procede de razones inseparables: la profunda decepción que provoca el régimen militar de 1976 (no sólo por la derrota de Malvinas) y el inestimable -y a la vez duro- proceso de aprendizaje democrático que transcurre entre 1983 y 1999. En estos breves pero intensos años, cargados de dificultades económicas y sociales, los argentinos pudieron demostrar su adhesión a la democracia como forma de gobierno. Si la legitimidad política es definida como el derecho de gobernar, la "justificación simultánea del poder y la obediencia" (Coicaud, 1997) queda siempre asociada a la conformidad de los procedimientos democráticos proclamados por las leyes, así como también a la aceptación de sus instituciones. Esta es la transformación de fondo que ha tenido lugar en nuestra sociedad. 


\section{Hacia un sistema de alternancia}

La alternancia es un elemento constitutivo de la democracia. Todos sabemos que la democracia no es posible sin el rol de la oposición y sin la presencia activa de los ciudadanos. Pero esto no es suficiente. Para no quedarse a mitad de camino y evitar tropiezos, ella necesita de la posibilidad de la alternancia entre los actores políticos, y de un sistema jurídico en el cual los preceptos constitucionales (que se refieren a los modos de sucesión del poder) desalienten en lugar de favorecer las ambiciones hegemónicas. Un régimen de competencia partidario debería estimular la rotación de los partidos en el poder, con el definido propósito de anular las voluntades hegemónicas que siempre tienden a fragmentar y debilitar la oposición. En este sentido, la alternancia es un problema tanto de los ciudadanos, capaces de optar, como de los partidos que deben ofrecer alternativas creíbles. De ahí que la conformación de un sistema semejante describe apropiadamente el grado de madurez política de los ciudadanos de un país.

La Argentina se halla en los umbrales de un cambio cualitativo en el sistema de competencia partidario. La falta de una tradición de alternancia ha privado a los ciudadanos de valiosas experiencias de aprendizaje democrático. Las señas de esa historia son las que hoy nos indican una marcha cuidadosa en terrenos desconocidos, pues si no existe tal tradición es porque ha prevalecido en nuestra práctica política una firme ambición hegemónica que dominó a gobiernos civiles y militares. No obstante, la experiencia democrática de estos dieciseis años ha revelado hechos desconocidos para la política argentina. El triunfo de Alfonsín en 1983 señala la novedosa derrota del justicialismo en elecciones libres y sin proscripciones, en tanto en 1989, por primera vezen nuestra historia, un gobierno democrático transfiere el poder por vía del sufragio universal a un partido de la oposición. Ello constituye un hito significativo que indica nuestra faimera alternancia en elecciones nacionales. La segunda alternancia tuvo lugar el 10 de diciembre de 1999 cuando la Alianza (entre el partido radical y el Frepaso) asumió el poder que dejó el justicialismo. Pero este hecho contiene a la vez otro rasgo inédito: por primera vez el peronismo es apartado del poder mediante una competencia electoral. De esta manera, el sistema de alternancia 
se incorpora como un elemento constitutivo y esencial de la democracia argentina, reafirmación que requiere de una cultura política capaz de convicciones plurales y de adquisición de hábitos de alternancia en los que pueda apoyarse la construcción institucional, más allá de los indispensables y claros preceptos legales que desalienten, en lugar de favorecer, las ambiciones hegemónicas. Como destaca Linz, la lógica de la alternancia permite la rendición de cuentas por políticas implementadas y la generación de expectativas para que actores importantes parmanezcan en el juego democrático (Linz, 1999).

Pero la concreción de una segunda alternancia en la Argentina estuvo asociada asimismo a la idea de coalición. Más allá de ser una buena propuesta para obtener mayoría, un esquema semejante puede contribuir a institucionalizar la democracia, a reducir los contenidos hegemónicos de la política, en la medida en que toda coalición implica concesiones y reconocimientos recíprocos que abren espacios donde el poder es compartido. En la Argentina, sin embargo, la continuidad de una estrategia de coalición nos presenta dudas. Por un lado, las experiencias de este tipo no forman parte de nuestra tradición política y, por otro, el carácter de fuerza menor del Frepaso en el interior de la coalición. Precisamente, uno de los riesgos por el que puede atravesar la Alianza es la pretensión de hegemonía que puede aparecer en algunos lugares del radicalismo. Ese será un excelente momento para demostrar la fortaleza de las convicciones aliancistas.

\section{Democracia y economía de mercado}

En el término de una década ha tenido lugar la transición del autoritarismo a la democracia y la transición de una economía dirigida a una economía de mercado. Los cambios político-institucionales se iniciaron, pues, con la instalación de la democracia a fines de 1983, y los económicos con la reforma de 1989 y la ley de convertibilidad de 1991, que sientan las bases de un nuevo sistema económico. La dualidad del proceso de transición, que moviliza a las instituciones políticas y económicas, deriva en la democracia política y en la economía de mercado. Raúl Alfonsín y Carlos Menem, con estilos y conductas diferen- 
tes, han sido los artífices de las "etapas fundacionales" de la nueva democracia argentina. Sin los logros de la transición política las reformas económicas no hubieran sido posibles.

La experiencia internacional ha demostrado que la democracia únicamente se ha desarrollado en el ámbito de las economías capitalistas, sin embargo el capitalismo ha sobrevivido, en lugares y momentos históricos diversos, sin la presencia de la democracia. A partir de esto, deseo esbozar dos cuestiones. La primera, recordar una distinción básica: capitalismo y mercado no son la misma cosa. La confusión se origina, según Lindblom, porque bajo los auspicios del capitalismo el mecanismo de mercado se convirtió en un organizador en gran escala de la vida económica (Lindblom, 1999) ${ }^{3}$. La segunda nos lleva a tener presente que la democracia no siempre triunfa en las economías de mercado, en algunas fracasa. ¿Cuál es la explicación? Tal vez habría que reiterar lo que decía Heilbroner en 1985: carecemos de una teoría general que nos dé una respuesta a ese interrogante (Heilbroner,1990, p.109-110).

La esclarecedora distinción -que mencioné anteriormente- fue establecida por Fernand Braudel. En rigor, el sistema de mercado es sólo una parte del capitalismo, pero no su totalidad (Heilbroner, 1996) ${ }^{4}$, quizá por ello se podría aseverar, junto a Lindblom, que el mercado es un recurso que puede emplearse tanto en las economías planificadas como en las que no lo son, en el socialismo como en el capitalismo (Lindblom, 1966, p.126). Los argentinos descubrimos en los últimos años a la democracia como orden político, pero sin prestar demasiada atención al valor que los mecanismos de mercado podían tener en el crecimiento de la economía, acaso más preocupados por entender, ante la presión de una fuerte corriente internacional, el surgimiento de un nuevo orden económico mundial al que había que integrarse. Entre las reformas económicas del presidente Menem, la estabilidad de la moneda es la que ha generado mayor adhesión, mucho más que la idea de economía de mercado. Hasta la fecha ésta sigue siendo una propuesta resistida en buena parte del pensamiento progresista.

\footnotetext{
${ }^{3}$ Me baso en este autor para hablar de mecanismos de mercado.

${ }^{4}$ Esa es la opinión do autor, especialmente en el cap. 4.
} 
Es por eso que la distinción entre capitalismo y mercado, entre economía de mercado y sociedad de mercado, resulta pertinente frente a la ortodoxia liberal y frente a la estricta visión de los planificadores. En este debate, mis objeciones no están dirigidas a los mecanismos de mercado sino al proyecto de un mercado autorregulador, a la idea del mercado gobernando a la sociedad ${ }^{5}$. La desintegración de la sociedad de mercado en 1930, a la que lacía referencia Karl Polanyi en 1944, no significó de manera alguna la desaparición de los mercados. El problema de los que no aceptamos la idea de una sociedad de mercado consiste en encontrar un reequilibrio entre Estado y mercado para permitir que las sociedades liberen aquellas energías que sean capaces de impulsar un ancho desarrollo económico, político y cultural, donde continuamente se resguarde una adecuada articulación entre libertad e igualdad. La experiencia soviética es determinante en cuanto a la intención de suprimir los mercados en sociedades mercantiles.Así como los mecanismos de mercado no consienten ser abolidos, tampoco el Estado puede ser retirado totalmente de la economía.

Más allá de los programas de ajuste estructural de los años ochenta, lo que se ha puesto en claro en los años noventa son los límites y riesgos de una estrategia económica basada en la dinámica exclusiva del mercado. De ahí el intento de recuperación del Estado. Las consecuencias económico-sociales del ajuste neoliberal ortodoxo han favorecido el giro hacia una mayor participación del Estado, aunque el mismo no alcance los niveles de antaño (Banco Mundial, 1997). Si, en verdad, hay pocas probabilidades de un retorno al intervencionismo, lo que se trata es de averiguar cómo se construye una "economía de mercado coordinada" (la denominación la tomo de Eric Verdier) -diferente tanto de una economía regulada por el Estado como de una economía de mercado neoliberal- en la cual la regulación social repose en una visión integral y articulada entre la acción estatal y el libre mercado.

El poder legítimo que se ha instalado en la Argentina desde 1983 es el resultado de la combinación de democracia política y economía de mercado. Al final del doble proceso de transición, nuestro país ha

${ }^{5}$ Desarrollo estas ideas en mi trabajo "Mercado y solidaridad social. Reflexiones a partir de la crisis del Estado de bienestar". 
logrado constituir un marco institucional adecuado que puede favorecer la expansión de la economía. Según Cortés Conde las causas de la declinación de la economía argentina deben buscarse más en la falta de marcos institucionales eficientes que en los propios problemas inherentes a ella (Conde, 1998). Los países avanzados crecieron, precisamente, a la luz de sistemas institucionales que fijaron reglas y acuerdos de convivencia social que permitieron el progreso de la economía. Con esto quiero decir que la eficacia de un sistema institucional, así como también la vigencia del Estado de derecho, es un componente indispensable de la construcción de una economía de alto desempeño, capaz de dar cuenta de las expectativas de la sociedad.

Durante mucho tiempo la democracia y el capitalismo (como orden económico-social) marcharon en la Argentina por senderos diferentes o, en el mejor de los casos, sus lugares de encuentros fueron ocasionales. Los cincuenta años de inestabilidad política y los veinte años de bajo desempeño económico que sólo mejoraron en la última década del siglo XX, son hechos históricos a tener en cuenta a la hora de explicar la creación de un poder legítimo, reconocido y aceptado por todos, de un poder capaz de ofrecer un marco institucional adecuado para el crecimiento económico. Pero no se trata sólo de eso, sino también del significado que reviste el voto de los mercados. Estos votan cotidianamente $y$, muchas veces, ponen en riesgo la gobernabilidad económica de las vulnerables democracias emergentes. Junto al voto de los ciudadanos se ubica el voto implacable del poder económico.

Al final del proceso de transición en la Argentina, la democracia y la economía de mercado, en una combinación inédita, deberán convivir buscando fórmulas de acción que favorezcan la continuidad de un poder legítimo, la igualdad social y un crecimiento sostenido. En este sentido, y aunque en el mundo se ha impuesto la economía de mercado, de lo que se trata -insistimos- es de discutir un reequilibrio entre Estado y mercado, luego de la declinación del período de ajuste estructural liderado por el neoliberalismo ortodoxo. Esta situación permite un giro favorable hacia una mayor participación del Estado, aunque la misma no alcance los niveles de antaño. A pesar de la necesaria reconstitución estatal, no hay probabilidades ni es conveniente el retorno al viejo intervencionismo. En este nuevo escenario hay que revisar la relación entre economía y política. 


\section{Concentración de poder y cultura política}

La construcción de un poder democrático en la Argentina ha estado atravesada por una tendencia a la concentración del poder y por las ambiciones de perpetuidad de muchos gobernantes militares y civiles. No hay que olvidar que la voluntad de poder y la cultura cultura política están fuertemente entrelazadas. La concentración del poder, decía Russell, ha sido siempre deseada por los gobernantes y no siempre ha sido resistida por los gobernados (Russel,1953, p.126-127). Sin esa contraposición, se puede desarrollar, entonces, una concepción de poder que en su configuración involucre tanto a los representantes como a los representados. Si la tentación hegemónica y la concentración constituyen los rasgos típicos de una determinada concepción de poder, interesa saber entonces cuál es el lugar exacto de los gobernados para descifrar la verdadera naturaleza de esa concepción. Si los ciudadanos creen en ese poder (representado y concentrado en la figura del Presidente civil o militar), y si todo poder produce efectos, no se puede soslayar el papel de la cultura política (Gadamer apud Cassirer, 1994, p. 16) ${ }^{6}$ en su constitución, en cuanto el poder también se fundamenta y despliega en un escenario de relaciones simbólicas.

Es sabido que los procesos de transformación no son lineales, por eso: ¿hasta dónde los cambios favorables en la cultura política de los años ochenta y noventa han podido borrar las marcas de nuestra historia? Pensemos en la larga tradición hegemónica que recorre nuestra historia. Más allá de que la mayoría de los ciudadanos, según las encuestas, rechazaba el proyecto reelecionista del presidente Menem, el hecho de que el tema haya ocupado el espacio que logró en los medios de comunicación, impulsado por los funcionarios del gobierno nacional, gobernadores de provincias peronistas y dirigentes del partido justicialista, aceptado por muchos ciudadanos, y por la mayoría de

\footnotetext{
Se la podría definir como un universo simbólico de creencias, costumbres y fenómenos políticos que comparten los miembros de una sociedad. La definición de cultura como "universo simbólico" pertenece a Ernest Cassirer (1994), referencia que he tomado del libro de Gadamer (1993, p.16). Coherente con su pensamiento, Cassirer considera que en vez de definir al hombre como animal rationale habría que definirlo como animal symbolicum.
} 
los miembros de la Corte Suprema, es en sí mismo preocupante para el desarrollo de una cultura política democrática. Creo que este debate habría sido impensable en una democracia estable con instituciones sólidas. El peligro residiría, precisamente, en un pasado, no totalmente superado, que puede volverse presente.

¿Qué tipo de poder configuró el presidente Menem durante sus 10 años de gobierno? La respuesta está vinculada con la discusión sobre la naturaleza de la democracia argentina. Este debate se inscribe en otro más amplio que abarca a las democracias emergentes de los países de América Latina y del Este. Para O'Donnell(1997) se ha constituido un tipo de democracia, con un peculiar perfil, que no encuadra en el clásico modelo de democracia representativa, y que adquiere la forma de regímenes duraderos no institucionalizados, a los cuales denomina "democracias delegativas". En réplica a O'Donnell, algunos autores como Juan Linz (1997), Stepan y Skach(1997) consideran que las características de la democracia delegativa tienen mucho de común con las patologías del sistema presidencial.

En el caso argentino, la hipótesis de O'Donnell ha dado lugar a un interesante debate sobre la experiencia presidencial de Carlos Menem. En mi opinión, el proceso de democratización tuvo lugar en un delicado contexto de ajuste estructural, de reforma del Estado, de control fiscal, de privatizaciones, y con la limitación impuesta por una voluminosa deuda externa. Así, el proceso de reformas estructurales (la reforma del Estado, entre otras) sólo fue posible mediante la aplicación de medidas de emergencia. Justamente, la concentración de poder nace de la declaración de emergencia. El poder legislativo "transfiere competencias" al poder ejecutivo mediante la sanción de las leyes de "Emergencia económica y social" y de "Reforma del Estado" de 1989/1990, haciéndose uso de la figura de la delegación legislativa y, a la vez, el poder ejecutivo ejercita "facultades legislativas" mediante la utilización abusiva de los decretos de necesidad y urgencia. Ambas medidas de excepción fueron incorporadas más tarde a la reforma constitucional de 1994.

En esas circunstancias, el gobierno de Menem exigió poderes excepcionales, que afectaron la división de poderes y esquivaron los sistemas de control, para encarar las innovaciones de la economía y la reforma del Estado que los cambios de época imponían. Se abre, por 
ende, una zona de tensión en el sistema institucional entre dos términos de una ecuación que no siempre coinciden: la crisis -que busca una respuesta-, y la "norma" - que busca su aplicación. Aquí, aparece una tensión no resuelta entre decisionismo y constitucionalismo, entre decisionismo y parlamentarismo ${ }^{7}$. A pesar de sus pretensiones decisionistas, el Estado de Menem no es un Estado hobbesiano dotado de una autoridad absoluta, es un Estado limitado por normas que buscan respuestas en una situación de crisis, obligado a estirar y fortalecer al máximo su autoridad -hasta llevarla a las fronteras del autoritaritarismo- para poder controlar la emergencia. El problema es que a lo largo de diez años (1989/1999), la lógica decisionista del poder ejecutivo fue permanentemente activada, tanto en la excepción como en la normalidad, hasta casi convertirse en un "poder por decreto". Se transforma en regla lo que debería ser una excepción.

Ahora bien, la legitimidad del poder de Menem se funda, además, en un liderazgo carismático (en crisis al final de su mandato a medida que las acciones de gobierno pierden eficacia), que no es incompatible con los procedimientos electorales de la democracia liberal, por lo que cabe la pregunta de si no es posible la calificación de "democracia liberal plebiscitaria" (Panebianco, 1999) ${ }^{8}$. Una vasta literatura ha dado respuesta a este interrogante (Schumpeter, Sartori, Dahl). No hay incompatibilidad entre liderazgo y democracia, lo importante es saber distinguir entre un liderazgo democrático y un liderazgo autoritario o totalitario (una cosa es Churchill, Roosevelt o De Gaulle y otra Hitler, Mussolini y Stalin).Aunque las democracias emergentes están enfrentadas a nuevas dificultades, no pueden escapar al desafío planteado por Weber a las sociedades de masas: el componente inevitablemente plebiscitario de las democracias modernas, condenadas, por ello, a oscilar entre la dominación burocrática y la dominación plebiscitaria (Weber apud Sintomer, 1999). Es cierto que en Max Weber la legitimidad política tiene un carácter racional (creencia en la legalidad) y un carácter carismático (fe en las cualidades extraordinarias de una persona). El

\footnotetext{
${ }^{7}$ Una discusión interesante del constitucionalismo liberal a partir de Weber y Schmitt se halla en Rune Slagstad (1999).

${ }^{8}$ Para una discusión sobre plebiscito y democracia, y democracia liberal plebiscitaria.
} 
peligro consiste en que en nombre de la necesidad histórica el lider carismático adopte una pose decisionista, considerándose con la capacidad suficiente para determinar unilateralmente lo que es bueno para la sociedad en esas circunstancias. En una tensión permanente se desenvuelven las democracias contemporáneas que parecen comprender, por un lado, la inevitabilidad de la concentración y personalización del poder (sobre todo en momentos de crisis) y, por otro, el deseo de evitar con el imperio de la ley el reino incontrolado del poder.

\section{Los nuevos tiempos de la política}

El triunfo electoral de la Alianza en octubre de 1999 fue percibido por muchos como el punto de partida de una renovación de la política. Es cierto, hay hechos nuevos en la política democrática que anticipan otras oportunidades: la posibilidad de la alternancia, el fin de los estilos hegemónicos, una transición del poder ordenada como nunca, un cambio institucional con reglas claras y estables, que frenó los sobresaltos políticos y económicos de antaño, la nueva convivencia en el poder a través de un pluralismo desconocido y un clima favorable a la reconstitución del Estado.

Sin embargo, otros hechos completan la fisonomía política de la Argentina actual. Lo que se puede observar aquí, y en otros lados, es una "crisis en el ejercicio normal de la ciudadanía" (Kriegel, 1998, p.67). Por un lado, hay un crisis de confianza en la clase política, cuya imagen se ha deteriorado aún más a partir de los escándalos de corrupción en el Senado. Crisis de confianza, entonces, en la representación política. Por el otro, hay una "crisis de integración social", que conduce directamente a los problemas de exclusión de buena parte de los ciudadanos.

A pesar de los logros que he mencionado con anterioridad, la construcción de un poder democrático en la Argentina esta atravesada por un conjunto de problemas que tienen que ver con con la búsqueda de igualdad social, con los deseos de seguridad, con la eliminación de la corrupción y con la calidad de las instituciones públicas, especialmente con las que imparten justicia. Estos problemas remiten a la crisis del ejercicio normal de la ciudadanía. Desafortunadamente, nuestras 
democracias encarnan un opaca combinación de desigualdad social con debilidad institucional.

Hay una marca de corrupción en la vida política que daña gravemente el funcionamiento de los partidos y las instituciones. Pareciera que hemos ingresado en una nueva etapa de la construcción de la democracia, que puede ser caracterizada como de "moralización de la política". Los escándalos del Senado son reveladores de la necesidad de cambios fundamentales. Se trata, más que nunca, de discutir el funcionamiento de las instituciones públicas y la reorganización de la democracia. En este sentido, ¿cómo perciben hoy los ciudadanos argentinos la vida política? Como todos sabemos, la política no transcurre hoy por su mejor momento. La mala reputación del término y la falta de honradez en algunos hombres políticos provocan, naturalmente, sentimientos de repudio. La palabra política -precisamente, la que permite la conversación entre los hombres en la esfera pública- se ha devaluado. En vez de expresión del bien común, se la concibe como sinónimo de beneficio privado. Las prácticas de corrupción en el Senado, acompañadas de una percepción de impunidad, terminan por agravar el malestar de los ciudadanos y amenazar el sistema democrático.

Esas prácticas han acelerado el estado de sospecha colectiva que pesa sobre la actividad política y los políticos. Pero el problema es aún más complejo. Por un lado, el Poder Judicial, encargado de esclarecer los hechos, está también sospechado, lo que genera dudas sobre la posibilidad de conocer la verdad y sancionar a los culpables. Por el otro, persiste entre los ciudadanos la incógnita de saber si el gobierno y la clase política podrán recuperar la credibilidad perdida. En efecto, la mayoría de los miembros del Senado ha reaccionado con "espíritu de facción", más preocupada por proteger intereses corporativos que por impulsar una profunda investigación que devuelva credibilidad a la clase política. Los indispensables cambios institucionales esperan su turno.

Paradójicamente, y coincidiendo con una opinión extendida, la crisis institucional ofrece una oportunidad a la democracia. Por eso, hacía alusión al surgimiento de una nueva etapa. En este nuevo escenario, complejo y perturbador, se han abierto las condiciones para desmontar un sistema de canjes y prebendas que ha funcionado con normalidad durante más de diez años y que ha servido para el 
enriquecimiento ilícito de algunos y la financiación de las actividades políticas de otros. Es una excelente oportunidad para mejorar la calidad de la vida política y desarraigar viejas prácticas corruptas.

Pero, ¿dónde anidan los temores? Quizá en aquella aseveración de Raymond Aron (1990): "la opinión que los ciudadanos se forjan de su régimen es inseparable de las cualidades o defectos del mismo". Las encuestas, y la calle, registran la creencia de los argentinos en los altos niveles de corrupción, lo que puede tener derivaciones peligrosas para la estabilidad de la democracia. La desconfianza colectiva en los políti$\cos$ y funcionarios abre espacio a las deslealtades al orden democrático. Este es el problema.

Sobre la democracia, quiero señalar además que puede ser también interpretada a partir de la capacidad de los ciudadanos para controlar el poder. La democracia, en fin, puede ser definida desde la capacidad crítica de los ciudadanos (en tanto es un régimen fundado sobre la opinión) para juzgar la actuación de sus representantes y, de esta manera, poder fiscalizar el proceso de toma de decisiones y el resultado que el mismo genera. En cuanto a las instituciones, me interesa subrayar la importancia de los partidos políticos en el funcionamiento de la democracia. Ellos son una institución inseparable del fundamento mismo de la democracia. La calidad de la democracia depende también de la calidad de los partidos. La democracia se perfecciona. La apuesta a su perfeccionamiento requiere la solidez de una línea de control de los ciudadanos sobre los poderes públicos y una mejor actuación de los partidos, muchas veces anquilosados en sus viejas formas de organización y en ciertas concepciones de la política que no se adaptan a los cambios de época.

Los desafíos para la Alianza no son pocos ni fáciles de resolver. De una coalición electoral exitosa, la Alianza debe convertirse en una coalición gobernante estable y competente, sobre todo porque en este tiempo han surgido nuevas demandas sociales e institucionales. En estos reclamos se hallan los difíciles pero no imposibles avances de la democracia. La convivencia democrática en la Argentina pone al descubierto, entonces, un presente novedoso y plagado de desafíos. El perfeccionamiento del sistema democrático dependerá en buena medida de su capacidad para aprender del pasado y de las decisiones orientadas 
al futuro. Si se procede de forma coherente se obtendrán lecciones ejemplares del pasado y se podrán obtener ventajas reales para enfrentar el futuro. Aunque la democracia a veces decepciona, no hay que olvidar, como decía Aron, que ella es el único régimen que incita a los gobernados a protestar contra los gobernantes(Aron, 1999,p.92).

\section{Referências Bibliográficas}

ARON, Raymond. Démocratie et totalitarisme. Paris:Folio-Essais, 1990.

ARON, Raymond. Introducción a la filosofía política. Barcelona: Paidós, 1999.

BANCO MUNDIAL. El Estado en un mundo en transformación. Washington, EE.UU., 1997

BOTANA, Natalio. El siglo de la libertad y el miedo. Buenos Aires: Editorial Sudamericana, 1998. Cap. 4-5.

CASSIRER, Ernest. Ensaio sobre o Homem: Introduçao a uma filosofia da cultura humana. São Paulo: Martin Fontes, 1994.

COICAUD , Jean-Marc. Légitimité et politique. Paris: PUF, 1997.

CONDE, Roberto Cortés. Progreso y declinación de la economía argentina. Buenos Aires: FCE, 1998.

FERRERO, Guglielmo. El poder: Los genios invisibles de la ciudad. Buenos Aires: Inter-Americana, 1943. p.157-158, 212.

GADAMER, Hans-Georg. Elogio de la teoría. Barcelona: Península, 1993.

GAUCHET, Marcel. La Révolution des pouvoirs. Paris : Editions Gallimard, 1995.

HEILbRONER, Robert. El capitalismo del siglo XXI. Barcelona: Península, 1996.

HEILBRONER, Robert L. Naturaleza y lógica del capitalismo. Barcelona: Península, 1990.

KRIEGEL, Blandine. La cité républicaine. Paris: Galilée, 1998

LINZ, Juan J. Las restricciones electorales de la democracia. In: Tiempo y democracia. Caracas: Editorial Nueva Sociedad, 1999. 
LINZ, Juan J. Democracia presidencial o parlamentaria. ¿Qué diferencia implica?" In: LINZ, JuanJ. ; VALENZUELA, Arturo (Comps.) La crisis del presidencialismo. 1. Perspectivas comparadas. Madrid: Alianza, 1997.

LINDBLOM, Charles E. Redescubrimiento del mercado. [S.1.: s.n.], 1966.

LINDBLOM, Charles E. Democracia y sistema de mercado. México: FCE, 1999.

O'DONNELL, Guillermo. ¿Democracia delegativa? en Contrapuntos. Ensayos escogidos sobre autoritarismo y democratización. Buenos Aires: Paidós, 1997.

PANEBIANCO, Angelo. El precio de la libertad. Losada: Buenos Aires, 1999.

QUIROGA, Hugo. Mercado y solidaridad social. Reflexiones a partir de la crisis del Estado de bienestar. Estudios Sociales. Revista Universitarial, n.1, 1991.

RUSSSELL, Bertrand. El poder en los hombres y en los pueblos. Buenos Aires: Losada, 1953.

SINTOMER, Ives. La démocratie impossible? Poltique et modernité chez Weber et Habermas. Paris: La Découverte, 1999.

SLAGSTAD, Rune. El constitucionalismo liberal y sus críticos: Carl Schmitt y Max Wber. In: ELSTER, Jon ; SLAGSTAD, Rune. Constitucionalismo y democracia. México: FCE, 1999.

STEPAN , Alfred ; SKACH, Cindy. Presidencialismo y parlamentarismo en perspectiva comparada. LINZ, JuanJ. ; VALENZUELA, Arturo (Comps.) La crisis del presidencialismo. 1. Perspectivas comparadas. Madrid: Alianza, 1997. 


\section{Abstract}

This article tries to examine the sixteen years of existence of the Argentinean democratic regimen, inaugurated at the end of 1983. Where is the Argentinean democracy located? What major changes have occurred? Considering this referential universe, the problematization of the relationship among Sate, market, and civil society is dealt with. Within one decade the transition from authoritarianism to democracy, and the transition of a directed economy to a market economy occurred. At the end of such double transitional process, democracy and market economy, in a new combination, shall live together, in search of formula of action which favor the continuity of a legitimate power, social equality, and a sustained growth. In that sense, even though in the world there is the imposition of market economy, the issue is to discuss a re-balancing between State and market. With no suspicion against the State whatsoever, our theme shall be: more of civil society instead of more of State or more of market. In these claims are the difficult yet not impossible advancements of democracy. The perfecting of the democratic system will largely depend upon its capacity to learn with the past and to make decisions orientated towards the future.

Key-words: legitimacy; democracy; Argentina.

\section{Resumo}

O artigo procura exanainar os dezesseis anos de vida do regime democrático argentino, inaugurado no final de 1983. Em que ponto se encontra a democracia argentina? Quais são as mudanças mais importantes que aconteceram? Com este universo de referência tratar-se á de problematizar a relação entre Estado, mercado e sociedade civil. No período de uma década ocorreu a transição do autoritarismo para a democracia e a transição de uma economia dirigida a uma economia de mercado. Ao término deste duplo processo de transição, a democracia e a economia de mercado, em uma combinação inédita, deverão conviver buscando fórmulas de ação que favoreçam a continuidade de um poder legítimo, a igualdade social e um crescimento sustentado. Neste sentido, e ainda que no mundo se tenha imposto a economia de mercado, a questão é discutir um reequilibrio entre Estado e mercado. Sem suspeitar do Estado, nosso lema será: mais sociedade civil em lugar de mais Estado ou de mais mercado. Nestas reivindicações encontram-se os difíceis, mas não impossíveis, avanços da democracia. $\mathrm{O}$ aperfeiçoamento do sistema democrático dependerá em boa medida de sua capaciclade em aprender com o passado e das decisões orientadas para o futuro.

Palabras-chave: legitimidade; democracia; Argentina. 